\title{
A microcomputer system for clinical bacteriology: experience of 12 months' trial
}

\author{
RJ COURCOL, M ROUSSEL-DELVALLEZ, GR MARTIN \\ From the Laboratoire de Bactériologie C, CHR Lille Hôpital A Calmette, Lille, France
}

SUMMARY A data processing system using microcomputers was developed in a hospital bacteriology laboratory processing more than 60000 specimens yearly. The purchase price of the hardware was frs $200000(£ 17500)$ and the software was written by the authors. The system has been running since May 1980 without general breakdown. The present configuration allows the processing of specimens, enquiries, scientific and administrative tasks but multiprogramming and cumulative reports are not possible.

Many computers are set up in biology laboratories because they allow accurate, reliable and speedy data processing. However data processing in microbiology differs from that in other laboratory departments because the data is largely textual, results are obtained in a multistep fashion and reports must be sent sequentially. ${ }^{1-3}$ Many kinds of data processing system have been described using either punched cards with off-site processing, ${ }^{4-7}$ laboratory computer, ${ }^{2}$ hospital computer ${ }^{1389}$ or a laboratory computer connected on-line with the hospital main-frame computer. ${ }^{10}$ In the last two cases, computers are used concurrently by other laboratories, clinical departments and/or administration. These systems have been developed for microbiology laboratories processing more than 100000 specimens yearly. The main interest of computerisation in microbiology is not only its use in laboratory routine or execution of administrative tasks but also accessing archived data to study sensitivity and epidemiology of isolated microorganisms in hospital so that the results may be applied in current practice. We have developed a data processing system using microcomputers in our laboratory which processes over 60000 specimens yearly. This paper describes our system and reports our experience of 12 months' trial.

\section{Material and methods}

\section{HARDWARE DESCRIPTION}

The microbiology system consists of 2 Silex microcomputers (Leanord, Haubourdin, France) with $64 \mathrm{~K} 8$ bit words of core, 4 Apple II Plus Microcomputers (Apple Computer Inc, Cupertino, California,

Accepted for publication 9 November 1981
USA) with $48 \mathrm{~K}$ bytes RAM connected to two disk drives each of $116 \mathrm{~K}$ capacity, a dual 8 inch floppy disk each of 1 MB capacity with 37-40 IBM compatibility (Leanord, Haubourdin, France), 1 Centronics 703 fast printer $(180 \mathrm{cps})$ (Centronics, Drogheda, Ireland) and 1 Microline slow printer (80 cps) (OKI, Electric Industry, Tokyo, Japan). All the microcomputers use the 6502 microprocessor. Each of the four units of the laboratory is equipped with a microcomputer and two disk drives. The other components are located in the secreterial office. The purchase price of the system was about frs 200000 (£17 500).

\section{SOFTWARE DESCRIPTION}

The computerised data system was developed for the particular needs of the laboratory and the application programs were written in Applesoft BASIC by the authors. No commercial software package was purchased. 'The memory capacity of the microcomputer precluded multiprogramming and required the sequential use of many programs to execute the different tasks. Each program is loaded in about 25 seconds. The processing of specimens is performed by four specific programs: patient and specimen identification, result entry, printing of reports and enquiries. There are utility programs such as initialising new disks or copying programs between disks. Two programs for administration duties process the monthly statistical and workload reports. A "clinical research" program allowed antimicrobial susceptibilities of organisms from each clinical department to be summarised. The programs are stored on a program diskette. Only the specimen processing programs and miscellaneous subroutines are saved on the program diskette in 
each laboratory unit. The two other diskettes used in a laboratory unit are data and print diskettes. The menu of programs appears when the microcomputer is switched on. All data are coded in numerical form except the patient's name and 31 characters of free text. There are four coded item groups:

-specimens (74 items of 2 digits),

-cells (44 items of 2 digits),

-micro-organisms in direct examination ( 25 items of 2 digits),

-micro-organisms in culture (199 items of 3 digits).

The coded items are associated with a quantitative or qualitative adjective that is a digit ranging from 0 to 9 . The significance of the latter is different according to item. The precision of coded items used by the technicians avoided hand-written additions on the computer report.

\section{INTRODUCTION OF THE SYSTEM}

The first studies on data processing in bacteriology began in June 1979. The development of the software required 29 man-months. At the outset, specific goals were defined to produce more efficient specimen processing, to reduce administrative duties and to allow scientific tasks such as antimicrobial susceptibilities and epidemiological studies. The specimen processing programs and the subroutine programs were running in our laboratory in May 1980 - the laboratory processes over 60000 specimens yearly. From the start, some software modifications were needed to improve their use and some new programs were introduced: administrative duty programs in July 1980, automatic billing procedure in December 1980 and antimicrobial susceptibility reports in January 1981.

\section{Description of the system}

The laboratory consists of four units and a secretarial office. Each unit processes the specimens of several clinical departments. The microcomputer, located in each laboratory unit, is similar in use to the video display terminals of bigger computer systems. At present all microbiology data are typed on a microcomputer and no peripheral equipment is connected on any microcomputer. Figure 1 presents an overview of the interactions between the microcomputer system functions and the laboratory work-flow. Each step in the process will now be described in detail.

\section{DATA ENTRY}

\section{Request entry}

On arrival in the laboratory, the specimens with the preprinted request forms are sent to the specific unit. The request entry program allows a clerk to type the patient and specimen identification on a formatted screen. The information is: patient's name, birth date, sex, hospital code number, date of admission, clinical department code, source of the specimen, investigation type, collection and arrival date. The patient identification is not re-entered when there are other specimens from the same patient: in this case the source of the specimen, the investigation type, the collection and arrival date only are typed. The microcomputer automatically gives the record number of the specimen-for example: $200-18(200=$ record number; $18=$ diskette number).

\section{Recording the results}

The results are written on the request form as a series of codes. The encoded result is typed by the technician who calls the record number of the patient identification stored on the data diskette. The identification appears on the video screen in about two seconds. The result type is variable depending on nature of the specimens. In this way, the report may be a combination of several result types such as microscopic examination, cytology, quantitative cytology, culture or antibiotic sensitivities. Only codes are typed. Each step of the result appears as decoded text on the screen and can be easily and quickly corrected. If antibiotic susceptibilities are required, one of eight subroutine programs is called according to the micro-organism (aerobic Gram-negative bacteria, staphylococci, streptococci, or anaerobic bacteria) or the specimen (urine or other specimens). Antibiotics appear on a formatted screen. Codes (" $S$ " = sensitive, "R" = resistant, "I" = intermediate, " $/$ " = not tested) are entered twice; the second entry checks the first one. When the analysis is completed, the billing is produced automatically. At the end of the report the overall result appears on the video screen, can be checked and must be validated before storing on the data diskette. When all results are typed and stored, they are transferred from the data diskette to the print diskette. The overall reports of a clinical department are loaded in the same file on the print diskette. The result entry time is about 90 seconds for an unskilled operator who types a result with antibiogram.

\section{Additional results}

In microbiology, results are obtained in a multistep fashion. In this way, reports are sequentially sent because one or several additional entries are necessary. All records are completed by calling the record number of the partially completed result. 


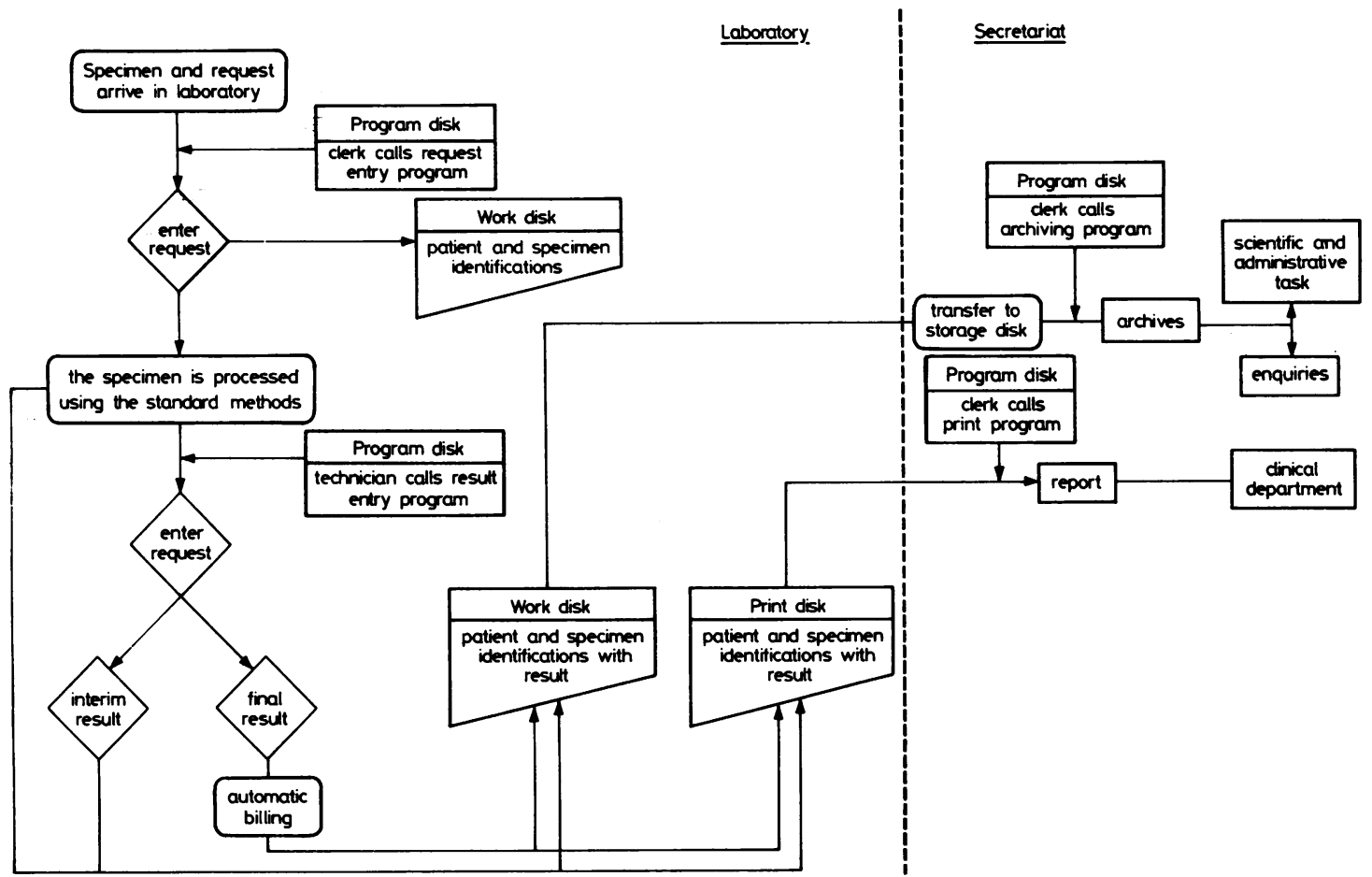

Fig. 1 Overview of the interactions between the microcomputer system functions and the laboratory workflow

\section{Processing errors}

There are many checks in the different programs to avoid errors and "nonsense" data. For instance, in the request entry program, the hospital code number is verified by a control key, the collection and arrival date cannot be less than the date of admission. In the result entry program, the size of the coded item string is determined according to the step of the result: multiple of three for microscopic examination, of four for cytology or culture: for example, it is impossible to type urinary cytology for a sputum result. The antibiotic susceptibilities are entered twice to avoid errors; moreover susceptibilities for some micro-organisms such as colistin for a Proteus sp cannot be typed. On the other hand, each step of the result can be immediately corrected.

\section{PRINTING OF REPORTS}

At the end of result entry, the print diskette is transferred to the secretarial office and can be edited. Reports are printed in twice-daily runs. The printprogram translates the codes stored on the print diskette and formats the report. No code appears in the report except antibiotics which are abbreviated. The antibiotic susceptibilities of a micro-organism are collected. The position of a message on the report depends on the number and quality of other codes used. A report is edited in 5-8 seconds and a report with one antibiogram is printed in 12 seconds. At the end of the printing, the print diskette is erased and returned to the laboratory unit.

\section{DATA RETRIEVAL}

The enquiry program is routinely used by the technicians and the clerical staff to reply to telephone requests. It allows enquiries about patient identification or result when calling record number or the first 1-5 letters of the name. It also produces a numerical list of specimens, the patient's name in alphabetical order and all cultures which have not been completed. The research time is equal to $2 \cdot 3$ seconds.

\section{BATCH PROCESSING}

Batch processing may be performed either by the microcomputer connected to the $1 \mathrm{MB}$ disk storage with IBM compatibility or by hospital computers. At present, batch processing is only done on the microcomputer. When all specimens on the data diskette are finalised, all data are stored on the $1 \mathrm{MB}$ disks. This storage disk allows batch-processing. Two programs process administrative duties. Cumulative reports processed in each unit are printed monthly; the report consists of the unit activity, collecting number, and number of specimens processed for each clinical department. Workload 
reports are printed when all specimens on the data diskette are finalised. The $1 \mathrm{MB}$ disc storage with 37-40 IBM compatibility allows details of the investigations to be transmitted to the hospital administrator.

Three scientific task programs are running at present. The exact results lie beyond the scope of this report but we describe our scheme of processing. Stored data are processed once every 3, 6, 12 months for each clinical department.
The first program is a compilation of susceptibility tests. Reports are edited in the following manner: collection date, patient's name, body source, micro-organisms, antimicrobial susceptibilities. The second program provides the number and the frequency of isolated micro-organisms for each clinical department. It can also provide the same (Fig. 2) for some kinds of specimens, such as blood cultures and spinal fluids, biological fluids-for example, pleural, ascites, dialysis etc-sputums, and urines. The same

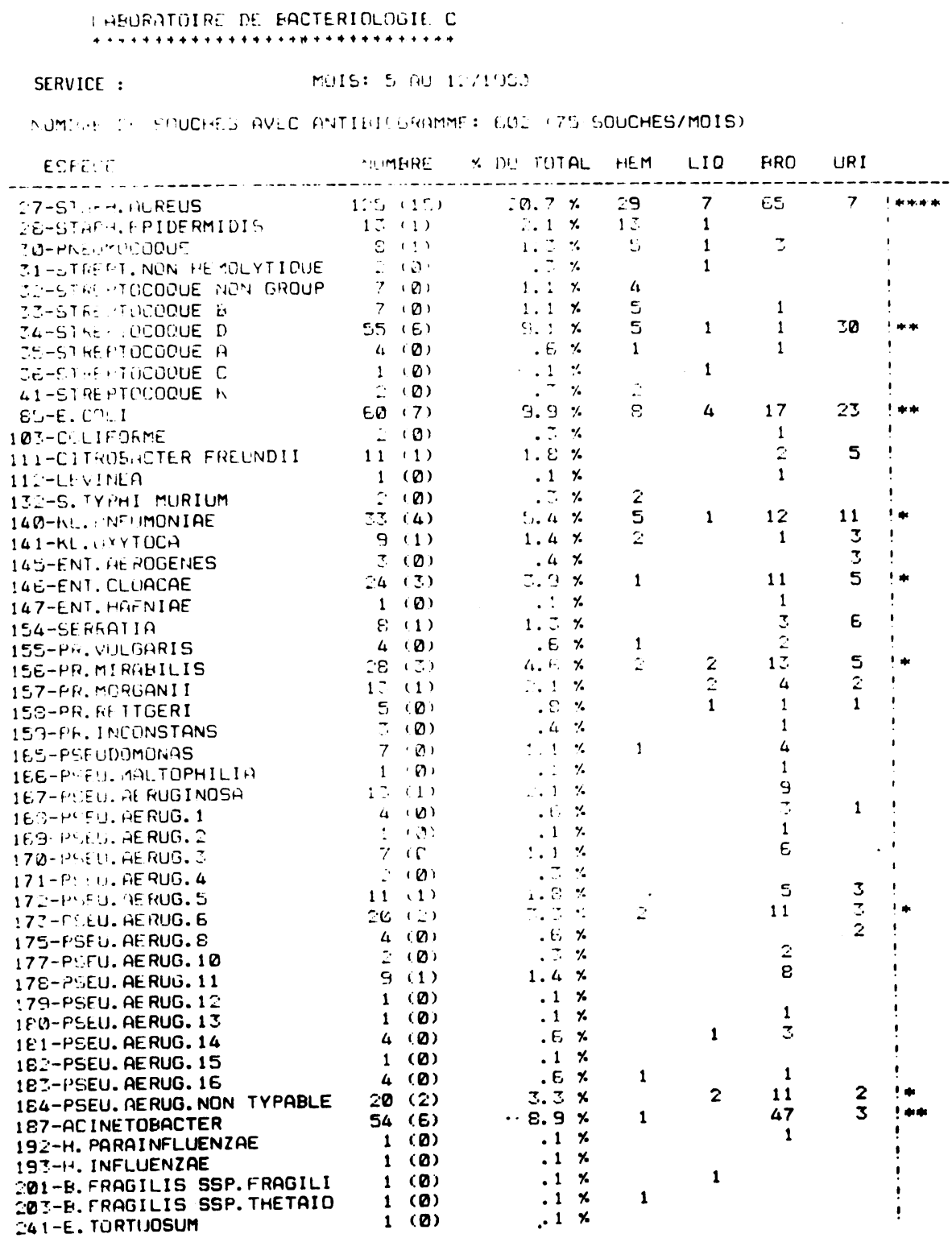

Fig. 2 Number and frequency of isolated micro-organisms for blood cultures, biological fluids, sputums and urines 
LAEORATOIRE DE GACTERIOLOGIE C

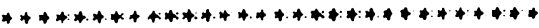

SERVICE :

MOIS: 5 AU $1: 11980$

GENRE : F'SEUDOMONAS

112 SOUICHES SUR UN TOTAL DE EQ2 SOUCHES (18. E\%)

\begin{tabular}{|c|c|c|c|c|c|c|c|c|c|}
\hline ATB & NB. SOUCHES & SEN & INT & RES & \multicolumn{2}{|c|}{ \% SENSIEILITE } & \multicolumn{2}{|c|}{ HISTOGRAMME $(*=5 x)$} & AT: \\
\hline & & & & & & & & $30 x$ & \\
\hline MP & 110 & 1 & 2 & 107 & .9 & $\%$ & & $!$ & AMP \\
\hline$A R$ & 108 & E9 & 0 & 39 & $E \Xi . \varepsilon$ & $x$ & $*: * * * * * * * * * * * * *$ & $!$ & CAR \\
\hline TN & 111 & $\because$ & D & 109 & $1 . \varepsilon$ & $\%$ & & $!$ & CTN \\
\hline$x T$ & 105 & $\Xi$ & 0 & 102 & $\therefore \varepsilon$ & $\%$ & *: & $!$ & BXT \\
\hline$F M$ & 107 & $\Xi$ & 0 & 104 & 2.8 & $\%$ & *: & $!$ & CFM \\
\hline$T X$ & 111 & 54 & $\Xi 2$ & 25 & $4 E . E$ & $\%$ & $*: *: * *: * *: * * * * *$ & $!$ & CTX \\
\hline$X M$ & $7 \varepsilon$ & 3 & 0 & 75 & $\Xi .8$ & $\%$ & $*$ & $!$ & SXM \\
\hline$E N$ & 100 & 59 & $E$ & 45 & $54 . E$ & $\%$ & 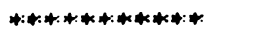 & $!$ & GEN \\
\hline TOB & $1: 1$ & 77 & 7 & 27 & E9. & $x$ & 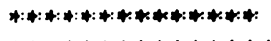 & $!$ & TOB \\
\hline$K N$ & ذ5: & 104 & 0 & 1 & 99.0 & $\%$ & 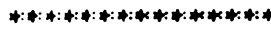 & $* * * * * * *$ & AKN \\
\hline IS & 110 & E9 & D & 41 & E:-7 7 & $\%$ & 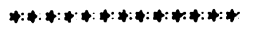 & $!$ & SIS \\
\hline ET & 101 & 45 & 55 & 21 & 44.5 & $\%$ & $*: *: *: *: * * *: * * *:$ & ! & TET \\
\hline-1 & 165 & $E$ & $E$ & 95 & 5.7 & $\%$ & \#: & $!$ & THI \\
\hline JL & $11=$ & 110 & 0 & 2 & 98.2 & $\%$ & 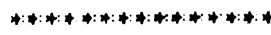 & $: * * * * *$ & $\mathrm{COL}$ \\
\hline SU & 111 & ت & 0 & $10 E$ & 4.5 & $\%$ & $*$ & $!$ & TSU \\
\hline & $1:$ & 7 & 0 & $\varepsilon$ & ت & $\%$ & $+*+* * * *+* * * *$ & $!$ & FOS \\
\hline & 11 & 0 & 1 & in & ? & $\%$ & & $!$ & NAL \\
\hline
\end{tabular}

Fig. 3 List of tested antibiotics with the different susceptibilities for a micro organism

strains isolated in several identical specimens are not added together. Thus one strain agrees with only one kind of specimen for a patient. Another scientific program provides the antimicrobial sensitivities of the isolated strains for each clinical department. Figure 3 shows such a report which gives the list of tested antibiotics, the number of strains tested for each of them, the different susceptibilities — that is sensitive, intermediate, resistant-the frequency of sensitive strains and a graphic representation of the latest data.

\section{Discussion}

Data processing in microbiology differs from that in biochemistry and haematology because data must be textual, abbreviations and results are obtained in a multistep fashion, and must be sent sequentially. ${ }^{1-3}$ These reasons together with reasons of cost of computer and software explain the reduced number of computer systems in small capacity microbiology laboratories. ${ }^{13}$ Therefore we have developed a data processing system using microcomputers. To our knowledge, the use of such a system is unique in a microbiology laboratory which processes over 60000 specimens a year.

The low cost of microcomputers with peripheral equipment was about frs $200000(£ 17500)$ and allowed us this investment. This cost is different from other systems using computers or minicomputers with purchase prices ranging from frs 380000 $(£ 33000)$ to frs $900000(£ 78500)$ with software. ${ }^{10}$ Our system has been running since May 1980 and no major breakdown has occurred proving the value of the hardware. Two failures were met with one disk-drive. However we never returned to manual reporting, as with some previously described systems. ${ }^{38911}$ Our system is flexible and modular allowing the avoidance of general breakdown. The system can be operated on a 24-hour basis, no routine maintenance being required, unlike other systems. The average terminal response time for the computer ranges from 2-5 seconds, ${ }^{19}$ sometimes up to 15 seconds. 9 With our microcomputers this terminal response time is always 2.3 seconds when a result is searched for. Apart from the advantages of the microcomputer, the main disadvantage is the small capacity core. Microcomputer memory allows neither large capacity programs nor multiprogramming like a computer. This drawback requires specific programs for each task to be changed and loaded.

Nevertheless, this operation is performed in 25 seconds. The $1 \mathrm{MB}$ disk storage with IBM compatibility is used for archiving. Batch-processing may be carried out either with our microcomputers or with 
hospital computers for scientific and administrative tasks. Until now, batch-processing was only done with a microcomputer.

Software of previously described systems was purchased $^{12310}$ or developed by the laboratories with the assistance of programmers. ${ }^{8912}$ In the present system, we have computerised data for the particular needs of our laboratory; the software was written by the authors.

The development of the software requires about 10 months for two persons in the developing phase and nine months for one man in the running phase. All programs are written in BASIC, thus explaining the ease of their development. Although a physician interested in computers is more suitable than a computer expert to design a medical laboratory system, ${ }^{1}$ we think equally that a programmer is also required to improve the efficiency of computer processing. Handwritten additions to the computer report are rare showing the precision of the coded items used by the technicians. The free-text ( 31 letters) allows the introduction in the result of some information about the analysis. However, the specimen identification is not as specific as those describing the type of material, the anatomy and site. ${ }^{19}$ All data are coded in numerical form because coded items are easier to learn than abbreviations or mnemonic groups of characters. The translation of codes on the report, similar to other previously described systems, ${ }^{13810^{-12}}$ is more explicit and easier to read than abbreviations. ${ }^{2}$

Another disadvantage of our system is that cumulative reports cannot be obtained as in other systems. ${ }^{1-3910}$ This drawback is due to the computer memory size. However in further developments, we could print a copy of the cumulative results for a given patient by batch processing. This copy might be obtained from the archives stored on the $1 \mathrm{MB}$ disk with IBM compatibility. These two disks with large capacity storage are the connection between our microcomputers and hospital computers. They allow the transfer of billing lists of patients without microbiological data. The IBM compatibility increases the potential of the microcomputer.

On the other hand, we found that telephone requests were reduced, probably due to faster transmission of the reports. The processing system maintains accuracy of results and information is more accessible than with a manual system.

One of the main interests of computerisation in bacteriology is to process the stored data. This processing allows an easier study of epidemiological data and antimicrobial sensitivities of isolated micro organisms in hospital. Some authors used computers for the quality control of antibiotic sensitivity testing, ${ }^{14}$ antibiotic susceptibility profiles, ${ }^{15-17}$ or epidemiological surveys. ${ }^{8}$ Kræméry et $a l^{16}$ found marked differences in resistance within individual medical services. Therefore the micro-organism antibiotic sensitivity and the epidemiological studies were performed for each clinical department and not the whole of the hospital. Our laboratory processes specimens of miscellaneous departments such as rehabilitation, reanimation, surgery, chest medicine, paediatrics, maternity and nephrology and our experience endorses Kreméry's view.

The present microcomputer system has been met with favourable responses from both technicians and clinicians. Computerisation in bacteriology allows the clinician to know susceptibility and epidemiology of micro-organisms of his own department and to prescribe a suitable therapeutic against them. It allows the follow-up of hospital epidemiology with sensitivities of different strains. Microcomputer processing is flexible and appears to be an inexpensive method of computerisation for small microbiology laboratories.

We are very grateful to Miss B Wanat for patient secretarial aid and to Mr John Hall for improving the English of this manuscript.

\section{References}

' Delorme J, Cournoyer G. Computer system for a hospital microbiology laboratory. Am J Clin Pathol 1980;74:51-60.

${ }^{2}$ Kobernick SD, Hendry PA, Greer JE. Coordinated computer reporting of microbiology data in the clinical laboratory. Am J Clin Pathol 1979;72:444-51.

${ }^{3}$ Ridgway GL, Batchelor J, Luton A, Barnicoat M. Data processing in microbiology: an integrated, simplified system.J Clin Pathol 1980;33:744-9.

4 Alexander MK, Conningale J, Johnson T, Poulter IR, Wakefield J. A data processing system for hospital bacteriology. J Clin Pathol 1970;23:77-80.

${ }^{5}$ Goodwin CS, Claire Smith B. Computer printing and filing of microbiology reports I - description of the system. J Clin Pathol 1976;29:543-52.

- Thabaut A, Durosoir JL, Saliou P, Guilloreau A, Chabannes Ph. Un système informatique en bactériologie clinique. Med Mal Inf 1979;9:647-53.

${ }^{7}$ Whitby JL, Blair JN. Data processing in hospital bacteriology: experience of 18 months' trial. J Clin Pathol 1972;25:338-43.

${ }^{8}$ Falcoz H, Brun Y, Fleurette J. L'ordinateur au service de la bactériologie: la surveillance épidémiologique en chirurgie cardiaque. Journées d'Information Médicale. Toulouse 5-7 Mars 1975. Colloque IRIA Tome 3:153-66.

9 Jorgensen JH, Holmes P, Williams WL, Harris JL. Computerisation of a hospital clinical microbiology laboratory. Am J Clin Pathol 1978;69:605-14.

${ }^{10}$ Lawrie DJ, Elin RJ, Gill VJ, Lewis TL, Mac Lowry JD, Witebsky FG. Microbiology subsystem of a total, dedicated laboratory computer system. J Clin Microbiol 1979;10:861-75.

"Andrews HJ, Vickers M. An assessment of one year of computer-assisted microbiology reporting at Charing Cross Hospital. J Clin Pathol 1974;27:185-91.

${ }_{12}$ Mitchison DA, Darrell JH, Mitchison R. A computer-assisted bacteriology reporting and information system.J Clin Pathol 1978;31:673-80. 
${ }^{13}$ Goodwin CS. Computer printing and filing of microbiology reports: 2 - evaluation and comparison with a manual system, and comparison of two manual systems. J Clin Pathol 1976;29:553-60.

14 Petralli J, Russell E, Kataoka A, Merigan TC. On-line computer quality control of antibiotic-sensitivity testing. $N$ Engl $J$ Med 1970;283:735-8.

is O'Brien TF, Norton RA, Kent RL, Medeiros AA. International surveillance of prevalence of antibiotic resistance. $J$ Antimicrob Chemother 1977;3:C 59-66.
${ }^{16} \mathrm{Kr}$ ×méry V, Grunt J, Rosival L, Calpał S. Antibiotic resistance in various medical services Infection 1979;7 suppl 2:216-9.

17 Wertz RK, Swartzberg JE. Computerised interpretation of minimum inhibitory concentration antimicrobial susceptibility testing. Am J Clin Pathol 1981;75:312-9.

Requests for reprints to: Dr RJ Courcol, Laboratoire de Bactériologie C, CHR Lille, Hôpital A Calmette, Boulevard du Pr J Leclercq, 59037 Lille Cédex, France. 